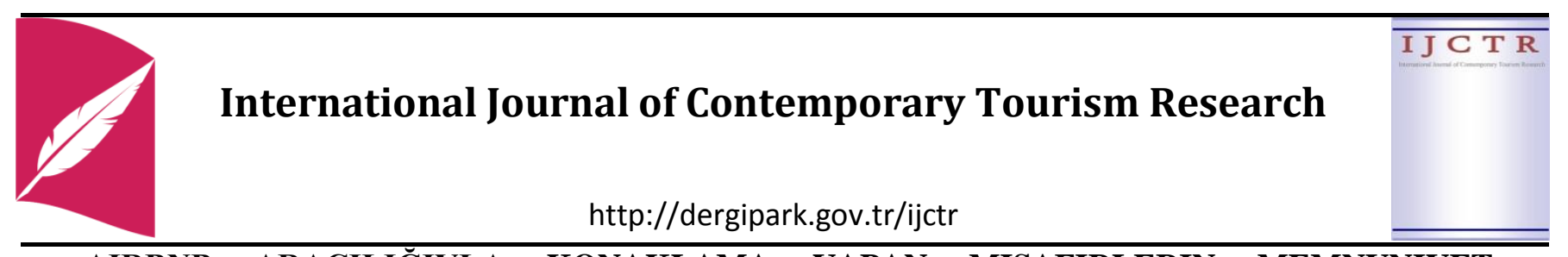

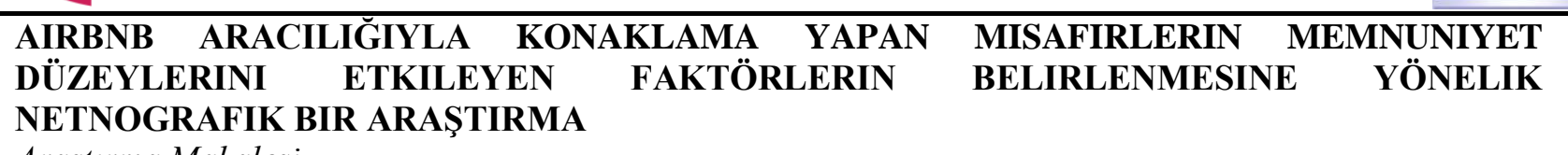

Araştırma Makalesi

Derya DEMIRDELEN ALRAWADIEH*, Mithat Zeki DİÇER**, Füsun İSTANBULLU DİNÇER***

\title{
ÖZET
}

\begin{abstract}
Alternatif konaklama olanakları son dönemlerde artmaya başlamıştır. Özellikle Airbnb gibi paylaşım ekonomisi kapsamında faaliyet gösteren girişimlere artan talep, konaklama sektöründeki rekabeti ciddi anlamda yoğunlaştırmıştır. Geleneksel konaklama işletmelerinde misafir memnuniyetini sağlayan faktörleri belirleyen birçok araştırma yapılmış olmasına karşın, Airbnb ile konaklama yapan misafirlerin memnuniyetlerini belirleyen faktörler üzerine henüz yeterince araştırma yapılmamışıır. Çalışmanın ana amacı Airbnb ile konaklamayı tercih eden misafirlerin memnuniyet faktörlerini belirlemektir. Bu amaçla, İstanbul'da kayıtlı Airbnb evleriyle ilgili olumlu yorumlar 'Inside Airbnb' veri tabanından alınarak netnografi ile içerik analizine tabi tutulmuştur. İlgili veri tabanında toplam 171158 yorumdan 350 olumlu yorum en güncel olandan başlamak üzere seçilerek analize tabi tutulmuştur. Geleneksel içerik çözümlemesi yöntemiyle elde edilen boyut ve temalar Nvivo12 ile kelime bulutu oluşturularak desteklenmiştir. Sonuçlara göre, Airbnb ile konaklayan misafirler, memnuniyetlerini ifade ederken en çok 'evin konumu', 'ev sahibinin tutumu' ve 'tesis veya odanın olanakları' üzerinde yorumlar yapmışlardır. Çalışma, Airbnb aracılı̆̆ıla konaklama yapan misafirlerin memnuniyet düzeylerini etkileyen faktörleri belirleyerek alan yazına teorik katkıda bulunmakta ve Airbnb ev sahiplerine yönelik öneriler sunmaktadır.
\end{abstract}

Anahtar Kelimeler: Airbnb, Misafir Memnuniyet Faktörleri, Netnografi, İstanbul

JEL Sınıflama Kodları: L83, Z31

\section{EXPLORING FACTORS DETERMINING SATISFACTION OF GUESTS STAYING WITH AIRBNB: A NETNOGRAPHIC APPROACH \\ Research Article}

\section{ABSTRACT}

With the growth and expansion of the alternative accommodation sector and especially the increasing demand for Airbnb offerings, the competition in the accommodation sector has significantly increased. Although several

\footnotetext{
* Doktora Oğrencisi, İstanbul Üniversitesi, Sosyal Bilimler Enstitüsü, deryademirdelen@ gmail.com, orcid.org/ 0000-0002-75542256

** Prof. Dr., İstanbul Üniversitesi, İktisat Fakültesi, İktisat Bölümü, mzdincer@istanbul.edu.tr, orcid.org/ 0000-0002-4928-8303

*** Prof. Dr., İstanbul Üniversitesi, İktisat Fakültesi, Turizm İşletmeciliği Bölümü, istanbul@istanbul.edu.tr, orcid.org/ 00000003-2338-2462

“Bu makale, 19-20 Nisan 2019 tarihleri arasında, Anamur'da gerçekleştirilen VIII. Ulusal IV. Uluslararası Doğu Akdeniz Turizm Sempozyumu'nda sözlü bildiri olarak sunulmuştur.”

"Demirdelen Alrawadieh D., Dinçer M. Z. ve İstanbullu Dinçer F. (2020). Airbnb Aracılığıyla Konaklama Yapan Misafirlerin Memnuniyet Düzeylerini Etkileyen Faktörlerin Belirlenmesine Yönelik Netnografik Bir Araştırma, International Journal of Contemporary Tourism Research, Vol 4: No: 1, p1-14, doi: 10.30625/ijctr.623218"
} 
attempts have been made to identify the factors that determine guest satisfaction in the traditional lodging businesses, little is known about the key factors that Airbnb guests appreciate during their stays. Therefore, the key objective of the study is to identify the main factors determining guest satisfaction in Airbnb accommodation businesses. Applying a netnography approach, online reviews posted about Airbnb properties operating in Istanbul were retrieved from 'Inside Airbnb' database and content analyzed. The most recent 350 reviews were selected from the total online reviews available (171158). The findings, supported by an Nvivo Word Cloud, suggest that the location of the house/facility, the host's attitude, and the house/room's facilities were frequently mentioned and praised by guests. The study adds to the limited literature on satisfaction with Airbnb and provides real-life implications for Airbnb hosts.

Keywords: Airbnb, Guest Satisfaction Factors, Netnography, Istanbul

JEL Classification Code: L83, Z31

\section{GİRİŞ}

Paylaşım ekonomisi şemsiyesi altında faaliyet gösteren Airbnb gibi alternatif konaklama girişimleri, önemli bir pazar dilimini cezbetmeyi başararak geleneksel konaklama işletmeleri için bir tehdit unsuruna dönüşmüştür (Zervas vd., 2017; Guttentag ve Smith, 2017; Alrawadieh, Guttentag, Cifci ve Cetin, 2020). Airbnb pazarının gelişmesi geleneksel konaklama işletmeleri için bir tehdit unsuru oluștursa da (Fang, Ye, Law 2016), var olan talep ile birlikte Airbnb'de kayıtlı konaklama tesisleri de hizla büyümeye devam etmektedir (Alrawadieh ve Demirdelen, 2019; Gurran ve Phibbs, 2017). Böylece dünya üzerinde milyonlarca turist Airbnb gibi alternatif konaklama imkânlarından yararlanmaya başlamıştır (Guttentag, Smith, Potwarka ve Havitz, 2018).

Turizmde paylaşım ekonomisine örnek olarak gösterilebilecek Airbnb, başarılı bir konaklama paylaşım platformu olarak değerlendirilmektedir (Liu ve Mattila, 2017). Geleneksel konaklama işletmelerinde misafir memnuniyetini belirleyen birçok çalışma yapılmış olmasına karşın (Yang, Mao ve Tang, 2018; Liu, Teichert, Rossi, Li ve Hu, 2017), alternatif konaklama tesislerini tercih eden misafirlerin memnuniyetlerini etkileyen faktörlere yönelik mevcut alan yazın oldukça sınırlıdır (Cheng ve Jin, 2019). Bu bağlamda, gerek dünyada gerekse Türkiye'de hızla büyüyen konaklama platformlarından biri olan Airbnb misafirlerinin memnuniyet düzeylerini etkileyen faktörlerin neler olduğunu anlamak mevcut alan yazına katkıda bulunmak açısından önem taşımaktadır. Bu pazarın gelecek vaat etmesiyle birlikte (Alrawadieh vd., 2020), Airbnb aracılığıyla konaklama yapan misafirlerin davranışları, deneyimleri ve memnuniyetlerini etkileyen unsurların belirlenmesine yönelik çalışmalar da hız kazanmaya başlamıştır (Lin, Fan, Zhang ve Lau, 2019).

Konaklama sektöründe artan rekabetle birlikte işletmeler için misafir memnuniyetinin sağlanması ciddi bir önem taşımaktadır. Konaklama deneyimi, misafir memnuniyetini şekillendiren en önemli unsurlardan biridir (Walls, Okumus, Wang ve Kwun, 2011). Bu deneyimin sonunda misafir memnuniyetinin sağlanması ile tatmin duygusu (Sangpikul, 2018; Kozak ve Rimmington, 2000; Kastenholz, Carneiro, Marques ve Loureiro, 2018); tekrar ziyaret etme niyeti (Cetin ve Dincer, 2014) ve olumlu ağızdan ağıza iletişim ile başkalarına tavsiye etme durumu artmaktadır (Kim, Ritchie ve Tung, 2010). Bu nedenle Airbnb ile konaklama yapan misafirlerin memnuniyet düzeyini etkileyen faktörleri belirlemek oldukça önemlidir. Airbnb gibi paylaşım ekonomisi içerisinde yer alan alternatif konaklama tesisleri, geleneksel konaklama tesislerine nazaran daha mikro düzeydedir. Dolayısıyla kullanıcılar tarafindan oluşturulan yorumlar, mikro düzeyde faaliyet gösteren tesisler için bilgi edinilmesi konusunda önemli bir unsurdur.

Airbnb gibi alternatif konaklama tesislerinde konaklamak, misafirler için eşsiz deneyimler sunmakta ve olanaklar, misafir memnuniyetini etkilemektedir. Misafir memnuniyeti hizmet pazarlamasının önemli bir parçası olduğundan $(\mathrm{Xu}$ vd., 2019), Airbnb platformuna kayitlı evlerde konaklayan misafirlerin memnuniyetleri belirlenmeli ve misafir memnuniyetini etkileyen faktörlerden hareketle gerek hizmet standartları, gerek ev ile ilgili özellikler, gerekse de ev sahibinin tutumu değerlendirilmelidir. $\mathrm{Bu}$ araştırmanın konusu da Airbnb gibi alternatif konaklama platformlarında konaklayan misafirlerin memnuniyetini etkileyen faktörleri incelemektir. $\mathrm{Bu}$ amaçla araştırmada Airbnb 
konaklama deneyimi yaşayan misafirlerin olumlu yorumları içerik analiziyle değerlendirilerek memnuniyeti etkileyen faktörler belirlenmiştir.

\section{KONAKLAMA IŞLETMELERINDE ELEKTRONIK AĞIZDAN AĞIZA İLETIŞIM VE MEMNUNIYET}

Tüketiciler, ürün veya hizmetle ilgili satın alma kararı almadan önce ortaya çıkabilecek riskleri azaltmak amaciyla farklı kaynaklardan bilgi alma eğilimindedir (Cantallops ve Salvi, 2014; Hussain, Ahmed, Jafar, Rabnawaz ve Jianzhou, 2017). İnsanların bilgi arayışları, ağızdan ağıza iletişimin etkisini internet üzerinden hızla genişletmiştir (Leong, Hew, Ooi ve Lin, 2019). Ürün, marka veya işletme hakkında internet üzerinden yapılan görüş ve deneyimler hızla geniş bir kitleye ulaşmaktadır (Yen ve Tang, 2015b; Ye, Law, Gu ve Chen, 2011). Konaklama sektörü elektronik ağızdan ağıza iletişimden (Electronic Word of Mouth- eWOM) güçlü bir şekilde etkilenmekte (Ladhari ve Michaud, 2015) ve bu etki tüketici davranışlarını olumlu veya olumsuz yönde şekillendirmektedir (Cantallops ve Salvi, 2014). Hizmetler soyuttur; dolayısıyla konaklama sektöründe tüketiciler satın alma kararındaki karmaşıklığı azaltmak amacıyla diğer insanların görüşlerinden ve deneyimlerinden yararlanabilmektedir (Yen ve Tang, 2019a; Min, Lim ve Magnini, 2015; Ye, Li, Wang ve Law, 2014).

Elektronik ortamda ağızdan ağıza iletişimin en önemli bilgi kaynağı kullanıcılar tarafından oluşturulan içeriklerdir (User Generated ContentUGC). Kullanıcılar tarafından oluşturulan içerikler hem potansiyel müşteriler için hem de işletme sahipleri için ürün veya hizmet hakkında önemli bir bilgi kaynağı sunmaktadır (Ye, Li, Wang ve Law, 2014). Potansiyel müşterilere yol gösteren bir araç olması (Liu ve Zhang, 2014; Kim, Lim ve Brymer, 2015); tavsiye niteliği taşıması (Radojevic, Stanisic ve Stanic, 2015), müşteri talepleri ve güvenlerini etkilemesi (Zhao, Xu ve Wang, 2019), seçim kararı almalarında ve riski azaltmalarında bir etken olarak görülmesi (Lo ve Yao, 2019) gibi pek çok konu, yapılan yorumların müşteriler açısından önemini ortaya koymaktadır. İşletme açısından değerlendirildiğinde ise, kullanıcılar tarafından oluşturulan içerikler; müşteri gereksinimlerini tanımlamak, pazar stratejileri oluşturmak, işletme performanslarının ortaya konulması, talebin artması ve tüketici memnuniyetini arttırmak açısından önemli stratejiler ortaya koymaktadır (Phillips, Zigan, Silva ve Schegg, 2015; Zhao, Xu ve Wang, 2019; $\mathrm{Xu}$ ve Li, 2016; Schuckert, Liang, Law ve Sun, 2019). Bu yorumlar, konaklama işletmesinin genel itibarını etkilediğinden (Radojevic, Stanisic ve Stanic, 2015), yapilan yorumlarla konaklama işletmelerinin finansal başarıları arasında bir etkinin var olduğu söylenmektedir (Alrawadieh ve Law, 2019; Xu ve Li 2016; Schuckert, Liang, Law ve Sun, 2019).

Çevrimiçi yorumlar gerek misafirler, gerekse işletmeler açısından önemlidir. Hatta çok fazla çalışma, misafirlerin memnuniyet faktörlerini ortaya koyarken kullanıcıların oluşturduğu içerikten yararlanmıştır (Zhao, Xu ve Wang, 2019; Alrawadieh ve Law, 2019). Konaklama deneyimi yaşayan misafirlerin çevrimiçi yorumlarda bulunmas1 ve memnuniyetlerini dile getirmesi ile elde edilen bilgiler misafirlerin memnuniyet faktörlerini ortaya çıkarmaktadır (Ahani, Nilashi, Ibrahim, Sanzogni ve Weaven, 2019). Nas1l ki kullanıcıların yapmış oldukları olumsuz görüşler işletmeler açısından müşteri kaybetme, yeni müşteri kazanma firsatını azaltma veya işletme itibarını zedeleme gibi tehditleri beraberinde getiriyorsa, görüşler olumlu olduğunda işletmeler yeni müşteriler çekmekte ve ürün veya hizmete karş1 mevcut müşterilerin sadakatini oluşturmaktadır (Guo, Barnes ve Jia, 2017; Alrawadieh ve Law, 2019). Çevrimiçi yorumlar potansiyel müşterilerin de memnuniyetlerini etkileyen unsurlardan biri olarak görülmektedir. Her ne kadar hizmetlerden elde edilen memnuniyet sübjektif değerlendirmelere açık olsa da misafirlerin konaklama deneyimleri, potansiyel misafirler için yol gösterici olma özelliği taşımaktadır. Misafir memnuniyetleri ise tekrar ziyaret etme, geri alım yapma, memnuniyet değerlendirmesi ile olumlu bir ağızdan ağıza iletişim olasılığını yükselterek (Cheng, Gan, Imrie ve Mansori, 2018) rekabet ortamında işletmelerin de hayatta kalmaları ve sürdürülebilirlikleri üzerinde rol oynar.

\section{AIRBNB PLATFORMUNA KAYITLI EVLERDE KONAKLAYAN MISAFIRLERIN MEMNUNIYETI}

Paylaşım ekonomisi bilgi ve iletişim teknolojilerinin gelişmesi, tüketici bilincinin hızla 
artması gibi etkenlerle birlikte ekonomik ve teknolojik bir olgu olarak ortaya çıkmıştır (Hamari, Sjöklint ve Ukkonen, 2016). Pek çok pazarı etkisi altına alan paylaşım ekonomisi (Schor 2016), özellikle turizm ve seyahat hizmetlerinde etkisini hızla hissettirmektedir (Ert, Fleischer ve Magen, 2016). Konaklama paylaşımında en fazla kullanım oranına sahip platformlardan biri olan Airbnb (Heo, 2016), evlerin / odaların kısa süreli kiralanmalarını sağlayan çevrimiçi bir uygulama olarak tanımlanmaktadır (Martin, 2016).

Turizm sektörü üzerindeki etkisi değerlendirildiğinde Airbnb, gerek arz gerekse talep açısından dünyanın en popüler konaklama paylaşım platformu olarak değerlendirilmektedir (Zekan, Önder ve Gunter 2019). Airbnb verilerine göre, dünyada 2,9 milyon ev sahibi bulunmakta ve her gece için ortalama 800 bin kişi Airbnb konaklamasından yararlanmaktadır (Airbnb, 2019). Türkiye ise dünyada yer alan bu potansiyele paralel olarak hızla büyümeye devam etmektedir (Alrawadieh ve Demirdelen, 2019).

Airbnb platformunda marka imajı büyük ölçüde kullanıc1 değerlendirmelerinden ve yapılan yorumlardan oluşmaktadır (Bridges ve Vásquez, 2018). Yapilan yorumlar ve konuk memnuniyeti Airbnb potansiyel tüketicilerinin satın alma süreçlerinde önemli rol oynamaktadır (Liu ve Mattila, 2017). Geleneksel konaklama işletmeleri için yapılan yorumlar nasıl ki otel seçimi ve tercihinde etkili oluyorsa $(\mathrm{Hu}$, Chen ve Chou, 2017), alternatif konaklama işletmeleri içerisinde yer alan paylaşım platformlarından biri olan Airbnb'de de, yapilan yorumlar kullanıciların tercihlerini etkilemektedir (Chen ve Chang, 2018). Müşteri incelemeleri hem ev sahipleri hem de potansiyel misafirler açısından gereklidir (Luo ve Tang, 2019). Bu noktada kullaniciların oluşturdukları içerikler önem kazanmaktadır (Varma, Jukic, Pestek, Shultz ve Nestorov, 2016).

Son dönemlerde, özellikle Airbnb platformuna kayitlı evlerde konaklama yapan misafirlerin motivasyonları, algıları ve tercihleri üzerine birçok çalışma yapılmış (Tussyadiah, 2015; So, Oh ve Min, 2018) ve memnuniyet düzeylerini etkileyen faktörlerin neler olduğu saptanmaya çalış1lmıştır (Priporas, Stylos, Vedanthachari ve Santiwatana, 2017; Liang, Choi ve Joppe, 2018). Misafirlerin geleneksel konaklama işletmelerinde otel seçimleri nasıl ki temizlik, konum, hizmet kalitesi gibi faktörlerden etkileniyorsa (Lutz ve Newlands, 2018); Airbnb platformu aracılığıly konaklama yapan misafirlerin memnuniyetini etkileyen faktörler arasında da; konum, tesis içi olanaklar, ev sahibi gibi benzer özellikler bulunmaktadır (Cheng ve Jin, 2019).

\section{YÖNTEM}

Çevrimiçi seyahat platformları, araştırmacıların yenilikçi araştırma tekniklerini kullanarak zengin ve daha az maliyetli veriler elde etmelerini sağlamıştır (Xiang, Schwartz, Gerdes ve Uysal, 2015). Bu araştırmada, İstanbul'da kayıtlı Airbnb evleriyle ilgili olumlu yorumlar 'Inside Airbnb' veri tabanından alınarak içerik çözümlemesi tekniğiyle incelenmiştir. Çalışmanın ana amacı; Airbnb platformuna kayıtlı evler ile ilgili olarak yapılan çevrimiçi yorumların incelenmesiyle misafir memnuniyetini etkileyen faktörleri belirlemektir. $\mathrm{Bu}$ amaca ulaşırken netnografi yöntemi uygun görülmüştür. Yenilikçi bir araştırma yöntemi olarak nitelendirilen netnografi yönteminde, çevrimiçi topluluklarda etnografi uygulanmaktadır (Kozinets, 2002). Dolayısıyla netnografi, çevrimiçi etnografi olarak değerlendirilmektedir (Kozinets, 2007). Son dönemlerde, bu yöntemin turizm araştırmalarında da sıkça kullanıldığı görülmektedir (Beaven ve Laws, 2007; Gursoy, Cai ve Anaya, 2017; Alrawadieh ve Alrawadieh, 2020). Bu çalışmada, 'Inside Airbnb' veri tabanında 2009-2018 y1llarına ait toplam 171158 yorum bulunmuştur. $\mathrm{Bu}$ yorumlardan toplam 350 olumlu yorum en güncel olandan başlamak üzere seçilerek analize tabi tutulmuştur. $\mathrm{Bu}$ veri tabanından birçok benzer çalışmada da yararlanılmıştır (Cheng ve Jin 2019; Ert ve Fleischer, 2019).

Kodlama sürecinde daha önce yapılan çalışmalara ve analize tabi tutulan verilere dayanılarak karma bir yaklaşım benimsenmiştir (Fereday ve MuirCochrane, 2006). Bu bağlamda, geniş bir alan yazın taraması yapılarak önce geleneksel konaklama işletmeleri (Barreda ve Bilgihan, 2013; Khoo-Lattimore ve Ekiz, 2014; Berezina, Bilgihan, Cobanoglu ve Okumus, 2016; Dinçer ve Alrawadieh, 2017; Liu vd., 2017; Alrawadieh ve Law, 2019) daha sonra Airbnb platformuna kayitlı tesisler (Cheng ve Jin, 2019; Ju, Back, Choi, ve Lee, 2019; Xu, La, Zhen, Lobsang ve Huang, 2019; Moon, Wei, ve Miao, 2019; Zhang, 2019) ile ilgili olarak misafir memnuniyetini etkileyen 
faktörler belirlenmiştir. $\mathrm{Bu}$ aşamadan sonra, mevcut faktörleri göz önünde bulundurarak (tümdengelim) ve verilere karşı açı görüşlü kalarak (tümevarım) bir sinıflandırma geliştirilmiştir. Misafir memnuniyetini etkileyen faktörler belirlenirken sadece olumlu yorumlar ele alınmıştır. İngilizce olarak paylaşılan yorumlar iki araştırmacı tarafından bağımsız olarak kodlanarak çözümlenmiştir. Bu yöntem objektif ve güvenilir bir kodlama sağlamaktadır (Lune ve Berg, 2016). $\mathrm{Bu}$ sürecin sonucunda; 908 unsur (ifade) 22 adet tema altında toplanmıştır; bu temalar ise üç ana kategori altında gruplandırılmıştır.

Geleneksel içerik çözümlemesiyle ortaya konulan boyut ve temalar nitel analiz programı olan NVivo 12'nin yardımılla kelime bulutu (Word Cloud) oluşturularak desteklenmiştir. NVivo analiz programı halen sadece İngilizce metinleri algıladığı ve çalışmadaki veriler (350 yorum) İngilizce olduğu için programdan elde edilen bulut kelime sıklığı İngilizce olarak oluşturulmuştur. NVivo siklık analizleri kullanılarak geleneksel içerik çözümlemesi desteklenmiştir ve kodlamanın güvenirliği sağlanmıştır (Sotiriadou, Brouwers ve Le, 2014).

\section{ARAŞTIRMANIN BULGULARI}

Araştırmada İstanbul'da Airbnb platformuna kayitlı evlerde konaklayan misafirlerin memnuniyetini etkileyen faktörler ile elde edilen bulgular 'konum' $(\% 36,7)$, 'ev sahibi' $(\% 32,3)$ ve 'tesis/oda olanakları' (\%31) olmak üzere 3 ana kategoride sınıflandırılmıştır (Tablo 1).

Tablo 1: Airbnb Misafirlerinin Memnuniyetini Etkileyen Faktörler

\begin{tabular}{|l|l|l|}
\hline Kategoriler & Stkllk & $\mathbf{\%}$ \\
\hline Konum & $\mathbf{3 3 3}$ & $\mathbf{3 6 , 7}$ \\
\hline Konum ile ilgili genel tutum (açıklama yapılmadan ifade edilen konum memnuniyeti) & 77 & 8,5 \\
\hline Turistik yerlere yakın olması & 60 & 6,6 \\
\hline Ulaşım olanaklarına yakın olması & 56 & 6,2 \\
\hline Ev veya odanın manzaraya sahip olması & 49 & 5,4 \\
\hline Kafe, restoran, bar, market, alışveriş merkezi gibi tesislere yakın olması & 39 & 4,3 \\
\hline Şehir merkezine yakın olması & 25 & 2,8 \\
\hline Bölgenin sakin/sessiz olması & 15 & 1,7 \\
\hline Bölgenin güvenli olması & 12 & 1,3 \\
\hline Ev sahibi & $\mathbf{2 9 3}$ & $\mathbf{3 2 , 3}$ \\
\hline Ev sahibinin tutumu (misafirperver, iyiliksever, yardımsever olması) & 197 & 21,7 \\
\hline Bölge ve şehir hakkında bilgi sağlama /yönlendirme & 34 & 3,7 \\
\hline Ücretsiz hizmetler sunması & 26 & 2,9 \\
\hline İletişimde kabiliyetli olması & 22 & 2,4 \\
\hline Dürüst olması & 10 & 1,1 \\
\hline Yabancı dil bilmesi & 4 & 0,4 \\
\hline Tesis ve oda imkânlart & $\mathbf{2 8 2}$ & $\mathbf{3 1 . 0}$ \\
\hline Tesis / oda genel özellikleri & 118 & 13,0 \\
\hline Temizlik & 77 & 8,5 \\
\hline Mobilyaların yeterliliği / kullanışlı olması & 28 & 3,1 \\
\hline Mutfak malzemelerinin yeterliliği / kullanışlı olması & 22 & 2,4 \\
\hline Odanın / evin dekorasyonu & 12 & 1,3 \\
\hline Odanın sessiz olması & 11 & 1,2 \\
\hline Oda içi olanaklar & 8 & 0,9 \\
\hline İnternet hizmeti & 6 & 0,7 \\
\hline Toplam & $\mathbf{9 0 8}$ & $\mathbf{1 0 0 \%}$ \\
\hline
\end{tabular}




\section{Konum}

Geleneksel konaklama işletmelerinde bir otelin konumu, genel otel deneyiminin (memnuniyet/memnuniyetsizlik) vazgeçilmez bir bileşeni olarak kabul edilmektedir (Masiero, Yang ve Qiu, 2019). Konumun uygunluğu konaklama talebini arttıracağı gibi misafir memnuniyetini de etkileyen temel özelliklerden biridir (Cró ve Martins, 2018). Geleneksel konaklama işletmelerinin yanı sıra Airbnb platformuna kayıtlı evlerde konum sıkça vurgulanan unsurlardan biri olarak görülmektedir. Bu bağlamda, evlerin büyük oranda şehir merkezlerine veya turistik destinasyonlara yakın alanlarda yer aldıkları görülmektedir (Eugenio-Martin, Cazorla-Artiles ve González-Martel, 2019).
Çalışmadan elde edilen bulgulara göre; konum ile ilgili yorumlar misafirlerin en çok ifade ettiği memnuniyet faktörleri arasında yer almaktadır. Konaklama deneyimi içerisinde bir evin / tesisin konum olarak turistik yerlere yakın olmas1, manzarasının olması, merkezi olması, çevresinde alışveriş olanaklarının bulunması gibi tüm özellikler misafirleri cezbeden ve memnuniyetlerini etkileyen faktörler olarak değerlendirilebilir. Şekil 1'e göre Airbnb platformuna kayıtlı evlerin siklıkla Taksim, Sultanahmet, Kadıköy gibi turistik destinasyonlarda ve merkezi konumlarda bulunması da çalışmadan elde edilen bulguları destekler niteliktedir.

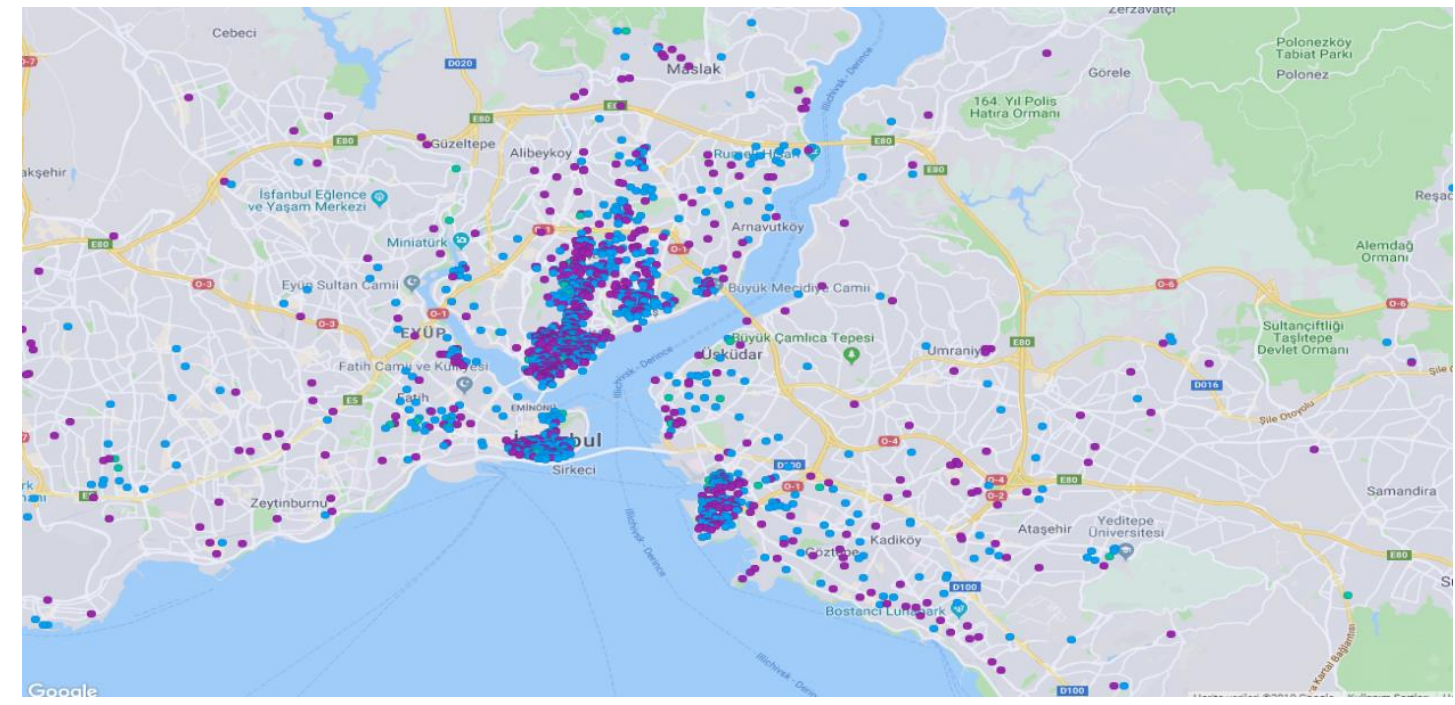

Şekil 1: İstanbul’da kayıtlı Airbnb evlerinin coğrafi dağılımları

Kaynak: AirDNA (2019)

'Konum' kategorisi içerisinde en çok vurgulanan konular arasında 'konum ile ilgili genel tutum' bulunmaktadir $\quad(\% 8,5)$. Yorumlar değerlendirildiğinde, misafirler konum hakkında detaylı bilgi paylaşmadan sadece genel bir yorumda bulunduğunda, ilgili yorum bu tema içerisinde değerlendirilmiştir. Bu temaya örnek olarak 'Konum güzel...' (K6); 'Daire güzel bir konumda' (K35) gösterilebilir. Konum ile ilgili olarak en s1k vurgulanan diğer konular; turistik yerlere yakın olması (örn. '...Galata Kulesi sadece birkaç dakikalık yürüme mesafesindedir...', K73); ulaşım olanaklarına yakın olması (örn. '...Metro yaklaşılk 10 dakika uzaklıktadır', K30); ev veya odanın manzaraya sahip olması (örn. '...Pencereden Boğaz manzarasina bakarak, tüm şehrin aydınlatmasinı izlersiniz...', K4) olarak ifade edilebilir.

\section{Ev Sahibi}

Elde edilen bulgulara göre misafirlerin ikinci sırada en çok vurguladığ konulardır. Konaklama deneyimi içerisinde ev sahibinin yardımsever ve misafirperver davranışları; destinasyon hakkında misafirleri bilgilendirmesi; kahvaltı, çay, Türk kahvesi gibi ikramlarda bulunması; iletişiminin iyi olması; dürüst olması (vaat ettiği hizmeti vermesi); yabanc1 
dili iyi kullanması gibi tüm özellikler misafirleri cezbeden ve ev sahibi ile ilgili konularda memnuniyeti etkileyen faktörler olarak değerlendirilebilir.

Konaklama tesislerinde sunulan hizmet, müşteri memnuniyetini etkileyen unsurlar arasinda değerlendirilebilir (Priporas, Stylos, Vedanthachari ve Santiwatana, 2017). Çalışmadan elde edilen bulguların yanı sira Tussyadiah (2016), Airbnb platformunda kayitlı tesislerde ev sahibinin konuklara sicakkanlı ve misafirperver bir ortam sağlaması ve destinasyonda yapılan etkinlikler hakkında misafirlere önerilerde bulunmasının da önemli olduğunu vurgulamıştır. Hatta konuk ve ev sahibi etkileşimi, işbirlikçi tüketimin önemli bir parçası olarak belirtilmiştir (Lalicic ve Weismayer, 2017). Bu durum geleneksel konaklama işletmelerindeki misafir memnuniyetini etkileyen faktörlerle de örtüşmektedir. Misafirlerin konaklama memnuniyeti turistik ürün veya hizmetlerle yakından ilişkilidir (Neal ve Gursoy, 2008). Müşteri memnuniyeti ise tüketici - çalışan (Airbnb'de ev sahibi) arasındaki ilişkiden etkilenir. Hatta bu ilişki, Airbnb aracılığıyla yapılan konaklamalarda misafir memnuniyetini etkileyen önemli bir faktördür (Lin, Fan, Zhang ve Lau, 2019). Belarmino vd. (2019) yapmış oldukları çalışmada misafir memnuniyetini etkileyen faktörler arasında ev sahibinin Airbnb aracılığıyla konaklama gerçekleştiren misafirler tarafindan en çok ifade edilen tema olduğunu vurgulamışlardır.

Çalışmadan elde edilen bulgular, ev sahibi ile ilgili olarak en çok vurgulanan temanın ev sahibinin genel tutumu olduğunu göstermiştir $(\% 21,7)$. Misafirler yaptıkları yorumlarda ev sahibi hakkında detaylı bilgi paylaşmadan, sadece genel bir yorumda bulunduğunda (misafirperver, iyiliksever, yardımsever gibi ifadeler) bu tema içerisinde değerlendirilmiştir. Bu temaya örnek; 'Ev sahibi çok iyi biri...' (K110) olarak gösterilebilir. Ev sahibi teması içerisinde vurgulanan diğer konular; bölge ve şehir hakkında bilgi sağlama / yönlendirme (örn. '...Ev sahibi akıcı Ingilizcesiyle şehir ve bölge hakkında bize bilgi verdi', K21) ve ücretsiz hizmetler sunmas1 (örn. '...Ev sahibi bizi Türk çayı ve kekle karşıladı...', 271) gösterilebilir.

\section{Tesis ve Oda İmkanları}

Elde edilen bulgulara göre; tesis ve oda olanakları ile ilgili yorumlar misafirlerin üçüncü sırada en çok vurguladığ Konaklama deneyimi içerisinde odanın veya tesisin güzel olması, geniş olması, dekorasyonunun güzel olmas1, sessiz olması, oda içi olanakların varlığ gibi tüm özellikler misafirleri cezbeden ve memnuniyetlerini etkileyen faktörler olarak değerlendirilebilir.

Geleneksel konaklama işletmelerinde misafir memnuniyeti; odaların ve ortak kullanım alanlarının uygunluğu, misafir odasının dekorasyonu, ambiyans, oda içindeki olanaklar (amenity) gibi pek çok unsurdan etkilenmektedir (Sukhu, Choi, Bujisic ve Bilgihan, 2019). Ayn1 durum Airbnb platformunda yer alan konaklama tesislerinde de geçerlidir. Hatta misafirler, Airbnb aracılığıyla gerçekleştirdikleri konaklamalarda oda tipi, iç tasarım, mevcut mobilyalar gibi pek çok unsuru önemsemektedirler (Lyu, Li ve Law, 2019). Dolayısıyla tesis ve oda içi olanakların varlığ misafirlerin memnuniyet(sizlik)leri üzerinde etkili olabilmektedir.

Elde edilen bulgulara göre; tesis ve oda olanakları kategorisi içerisinde en çok vurgulanan konular arasında tesis / odanın genel özellikleri bulunmaktadır (\%13). Misafirler tesis veya oda hakkında detaylı bilgi paylaşmadan sadece genel bir yorumda bulunduğunda (güzel, kaliteli, ferah, geniş, kullanışlı gibi ifadeler) bu tema içerisinde değerlendirilmiştir. Bu temaya örnek; '... Odalar geniş ve ferah' (K22) olarak gösterilebilir. Tesis ve oda olanakları içerisinde en vurgulanan diğer konu ise temizliktir. Örnek olarak; '...Odalar çok temiz...' (K100) gösterilebilir.

\section{Diğer Faktörler}

Sayılan bu kategori ve temalar dişında birkaç misafir, otantiklik ve fiyat ile ilgili olumlu yorumlarda bulunmuşlardır. Airbnb aracılığıyla konaklama deneyimi içerisinde geleneksel konaklama deneyimine nazaran otantik deneyim yaşama isteği Airbnb platformunda yer alan tesislerin tercih edilebilirliği üzerinde etkilidir (Paulauskaite, Powell, Coca-Stefaniak ve Morrison, 2017; Mody, Hanks ve Dogru, 2019; Guttentag ve Smith, 2017; Alrawadieh ve Demirdelen, 2019). Örnek olarak; '...Istanbul'u keşfetmek isteyen, yerel halkın yaptığl yerlerde alışveriş yapmak ve yerel halkla ayn yerlerde yemek yemek isteyen kişilere bu evi tavsiye ediyoruz...' (K77); '...Beni bu evde sicak hissettiren Türk insanıla etkileşime girebilme 
deneyimi' (K182) yorumları otantik deneyim temas1 içerisinde değerlendirilebilir. Airbnb platformuna kayıtlı evlerin geleneksel konaklama işletmelerinden daha uygun fiyatlı olduğu düşüncesi ve bu sayede turistlerin maliyet tasarrufu elde ettiği de (Guttentag, 2015; Oskam ve Boswijk, 2016; Alrawadieh ve Demirdelen, 2019) söylenebilir. $\mathrm{Bu}$ temaya örnek olarak '...Bu ev, şehri mükemmel bir fiyata keşfetmek için harika bir ev' (K62) gösterilebilir. Ancak bu gibi yorumlar sayıca az olduğundan siniflandırılan kategoriler içerisinde değerlendirilmemişlerdir.
Airbnb aracılığıyla konaklama yapan ve memnuniyetini ifade eden misafirlerin yapmış oldukları 350 olumlu yorumla ilgili kategori ve temalar oluşturulduktan sonra Nvivo 12 programı yardımıyla kelime bulutu oluşturulmuştur. Nvivo 12 programıla birlikte gerçekleştirilen kelime bulutu analizinde, içerik analizinde bulunan temaların desteklendiği görülmektedir. Şekil 2, Nvivo 12 programına göre 350 yorumdan en çok tekrarlanan sözcükleri göstermektedir. Sayfadaki yorumlar İngilizce olarak yer aldığından sıklık tablosu da İngilizce olarak çıkarılmıştır.

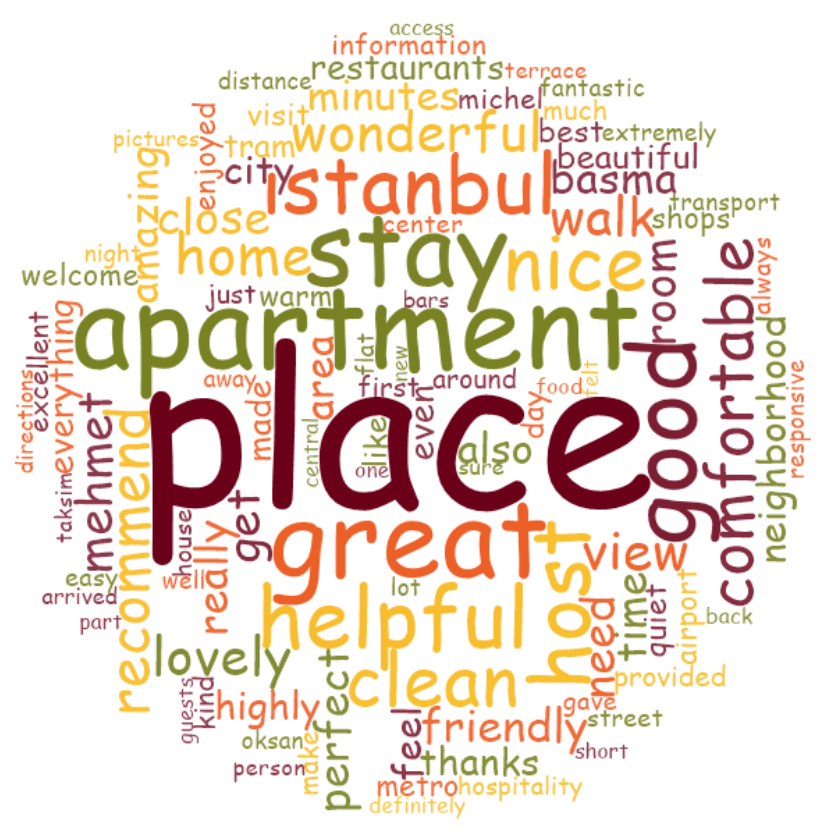

Şekil 2: Nvivo sıklık analizi sonucunda en çok kullanılan sözcükler

Nvivo sıklık analizi sonuçlarına göre en çok kullanılan veya tekrarlanan 10 sözcük ve eş anlamlarının sıklıkları çıkarılmıştır. Sıklık tablosuna göre en çok kullanılan kelimenin "place" (ev, mekan) olduğu görülmektedir. Takibinde en çok; "apartment" (daire), "great" (mükemmel), "stay" (konaklama), "'good"' (iyi), 'helpful', (yardımsever), 'host'” (ev sahibi), 'Istanbul" (İstanbul), 'nice" (güzel) ve "clean" (temiz) kelimeleri tekrarlanmıştır. Nvivo'nun desteğiyle oluşturulan kelime bulutundan anlaşıldığ1 üzere, tesisin konumu ile ev sahibine yönelik özellikler Airbnb aracılığıyla konaklama yapan misafirlerin memnuniyetini belirleyen en önemli faktörler olarak ortaya çıkmaktadır.

\section{SONUÇ VE ÖNERILER}

Çalışmadan elde edilen bulgulara göre, tesisin konumu, ev sahibi ve tesis veya oda olanakları Airbnb aracılığıyla konaklama yapan misafirlerin yapmış oldukları değerlendirmelerde en çok ifade edilen konular arasında değerlendirilmektedir. Konum, misafir memnuniyetinde en önemli faktörler arasında yer alır (Barreda ve Bilgihan, 2013; Khoo-Lattimore ve Ekiz, 2014; Ren, Zhang ve Ye, 2015; Liu vd., 2017). Hatta Rice ve Khanin (2019)'a göre, turist memnuniyeti konuma göre (konaklama yerleri, turistik alanlar, alışveriş olanakları vb.) şekillenebilir. Benzer şekilde elde edilen verilere göre konum ve konum ile ilgili ifadeler (şehir merkezine yakınlık, turistik yerlere yakınlık, ulaşım olanaklarına yakınlık gibi), 
Airbnb aracılığıyla konaklama yapan misafirlerin de memnuniyet düzeylerini etkilemektedir.

De Carlos, Alén, Pérez-González ve Figueroa (2019)'a göre turizm sektörü gibi hizmet işletmelerinin yaygın olduğu sektörlerde, misafir memnuniyeti büyük ölçüde hizmeti sunan kişilerle doğrudan etkileşime bağlıdır. Benzer şekilde, Airbnb ile ilgili yapılan birçok çalışmada da platforma kayitlı tesislerin ev sahipleri ile misafirleri arasındaki ilişkinin önemi vurgulanmıştır (Wang ve Jeong, 2018; Alrawadieh ve Alrawadieh, 2018). Bu çalışmada da ev sahibi ile ilgili olumlu ifadeler misafir memnuniyetini ikincil olarak etkileyen konular arasında değerlendirilmiştir.

Çalışmada oda, temizlik, mobilyalar, dekorasyon, oda içi olanaklar gibi tesis ve oda olanaklarının olumlu yorumlar aldığı görülmüştür. Tesis ve oda olanakları ile ilgili olumlu ifadeler misafir memnuniyetini üçüncül olarak etkileyen konular arasındadır. Park, Yang ve Wang (2019)'a göre de turizm sektörü içerisinde misafir memnuniyetinin temizlik, tesis içi olanaklar, oda kalitesi, yemek olanakları gibi birçok faktörden etkilendiği sonucuna ulaşılmıştır.

Araştırma, geleneksel konaklama işletmeleriyle rekabet edebilir konuma gelen Airbnb platformuna kayitlı konaklama tesislerinde konaklayan misafirlerin memnuniyet düzeylerini etkileyen faktörleri incelemektedir. Elde edilen bulgular doğrultusunda, Airbnb aracılığıyla konaklayan misafirlerin memnuniyetini etkileyen faktörler belirlenerek mevcut alan yazına teorik katkıda bulunulmaya çalışılmıştır. Türkiye'de Airbnb platformuna kayitlı konaklama tesisleri misafir konaklamaları açısından tercih edilebilir olmasına rağmen, Türkçe alan yazının bu tesislerde konaklayan misafirlerin memnuniyet düzeylerini etkileyen faktörlerin neler olduğunu belirleme konusunda oldukça sınırlı olduğu görülmektedir. Çalışmadan elde edilen öneriler gerek ev sahipleri, gerekse geleneksel konaklama işletmeleri açısından önem taşımaktadır. Airbnb platformunda kayıtlı konaklama tesislerinde misafirlerin memnuniyetini etkileyen faktörlere göre arz olanakları yaratmanın misafirlerin memnuniyet düzeylerini arttıracağı düşünülmektedir. İtibarına önem veren alternatif konaklama sahiplerinin konumun uygunluğu, misafir ilişkileri ve oda-ev olanaklarına daha fazla önem vermeleri gerekmektedir. Çünkü Airbnb platformuna kayıtlı evlerde konaklayan misafirlerin yapmış oldukları genel yorumlar hizmet geliştirici ifadeler olarak değerlendirilebilir. Aynı zamanda Airbnb üzerinden ev veya oda sunmayı / paylaşmayı düşünen ev sahipleri için araştırmadan elde edilen bulgular önemli bir yol haritası sunmaktadır.

Bulgular, geleneksel konaklama işletmeleri açısından da önem taşımaktadır. Çünkü Airbnb, göz ardı edilemeyecek bir hızla büyüdüğünden; geleneksel konaklama işletmelerine zaman zaman rakip olma yolunda ilerlemektedir. $\mathrm{Bu}$ nedenle geleneksel konaklama işletmelerinin de gerçekçi bir bakış açısıyla rekabet ortamında hizmet kalitesini iyileştirmesi ve memnuniyet odaklı bir hizmet anlayışı geliştirmesi gerekmektedir.

İstanbul'da Airbnb platformunda kayıtlı tesislerde konaklayan misafirlerin olumlu yorumlarını değerlendiren bu çalışmanın bazı kısıtları bulunmaktadır. Araştırmanın kısıtları arasında; sadece İngilizce yorumlara yer verilmiş olması, yalnızca tamamen olumlu yorumların ele alınması ve incelenen yorumlarin sayıca kisitlı olması yer almaktadır. Gelecekteki araştırmalar açısından bazı öneriler de sunulabilir. Airbnb platformuna kayıtlı evlerde konaklayan misafirlerle geleneksel otel işletmelerinde konaklayan misafirler arasındaki memnuniyet faktörlerinin kıyaslanması alan yazının geliştirilmesi açısından önemli görülmektedir. $\mathrm{Bu}$ sayede geleneksel konaklama işletmelerinin yanı sıra Airbnb konaklama evlerinde yapılan çalışmaların mevcut yazını da genişletilmiş olacaktır. $\mathrm{Bu}$ araştırmada Airbnb aracılığıla konaklama yapan misafirlerin memnuniyetlerini etkileyen faktörler ortaya konulmuştur. Gelecekteki araştırmalarda Airbnb evlerinde konaklayan misafirlerin, hem memnuniyeti hem de şikayeti araştırabilir.

\section{KAYNAKÇA}

Ahani, A., Nilashi, M., Ibrahim, O., Sanzogni, L., \& Weaven, S. (2019). Market segmentation and travel choice prediction in Spa hotels through TripAdvisor's online reviews. International Journal of Hospitality Management, 80, 52-77.

Airbnb (2019), Airbnb Genel Bakış, 08 Mayıs 2019 tarihinde https://www.airbnb.com.tr/host/homes?from_nav= 1 adresinden alınmıştır. 
Airdna, (2019). Market Overview. 10 Şubat 2019 tarihinde https://www.airdna.co/vacation-rentaldata/app/tr/default/istanbul/overview adresinden alınmıştır.

Alrawadieh Z.ve D. Demirdelen (2019), Turizm ve Ağırlama Endüstrisinde Paylaşım Ekonomisi, Detay Yayıncilık

Alrawadieh, Z., \& Alrawadieh, Z. (2018). Exploring entrepreneurship in the sharing accommodation sector: Empirical evidence from a developing country. Tourism Management Perspectives, 28, 179-188.

Alrawadieh, Z., \& Alrawadieh, Z. (2020). Developing a typology of tourist harassment in archeological sites: a netnographic approach. Journal of Tourism and Cultural Change, 18(2), 96-112.

Alrawadieh, Z., \& Law, R. (2019). Determinants of hotel guests' satisfaction from the perspective of online hotel reviewers. International Journal of Culture, Tourism and Hospitality Research, 13(1), 84-97.

Alrawadieh, Z., Guttentag, D., Cifci, M. A., Cetin, G. (2020). Budget Hotels' Perceptions of and Responses to Airbnb: Evidence from Istanbul. International Journal of Contemporary Hospitality Management. 32(2), 588-604.

Beaven, Z., \& Laws, C. (2007). 'Never Let Me Down Again': Loyal customer attitudes towards ticket distribution channels for live music events: A netnographic exploration of the US leg of the Depeche Mode 2005-2006 World Tour. Managing Leisure, 12(2-3), 120-142.

Barreda, A., \& Bilgihan, A. (2013). An analysis of user-generated content for hotel experiences. Journal of Hospitality and Tourism Technology, 4(3), 263-280.

Belarmino, A., Whalen, E., Koh, Y., \& Bowen, J. T. (2019). Comparing guests' key attributes of peer-to-peer accommodations and hotels: mixedmethods approach. Current Issues in Tourism, 22(1), 1-7.

Berezina, K., Bilgihan, A., Cobanoglu, C., \& Okumus, F. (2016). Understanding satisfied and dissatisfied hotel customers: text mining of online hotel reviews. Journal of Hospitality Marketing \& Management, 25(1), 1-24.

Bridges, J., \& Vásquez, C. (2018). If nearly all Airbnb reviews are positive, does that make them meaningless?. Current Issues in Tourism, 21(18), 2057-2075.

Cantallops, A. S., \& Salvi, F. (2014). New consumer behavior: A review of research on eWOM and hotels. International Journal of Hospitality Management, 36, 41-51.

Cetin, G., \& Dincer, F. I. (2014). Influence of customer experience on loyalty and word-of-mouth in hospitality operations. Anatolia, 25(2), 181-194.

Chen, C. C., \& Chang, Y. C. (2018). What drives purchase intention on Airbnb? Perspectives of consumer reviews, information quality, and media richness. Telematics and Informatics, 35(5), 15121523.

Cheng, B. L., Gan, C. C., Imrie, B. C., \& Mansori, S. (2018). Service recovery, customer satisfaction and customer loyalty: evidence from Malaysia's hotel industry. International Journal of Quality and Service Sciences.

Cheng, M., \& Jin, X. (2019). What do Airbnb users care about? An analysis of online review comments. International Journal of Hospitality Management, 76, 58-70.

Cró, S., \& Martins, A. M. (2018). Hotel and hostel location in Lisbon: looking for their determinants. Tourism Geographies, 20(3), 504523.

De Carlos, P., Alén, E., Pérez-González, A., \& Figueroa, B. (2019). Cultural differences, language attitudes and tourist satisfaction: a study in the Barcelona hotel sector. Journal of Multilingual and Multicultural Development, 40(2), 133-147.

Dinçer, M. Z., \& Alrawadieh, Z. (2017). Negative word of mouse in the hotel industry: A content analysis of online reviews on luxury hotels in Jordan. Journal of Hospitality Marketing \& Management, 26(8), 785-804.

Ert, E., \& Fleischer, A. (2019). The evolution of trust in Airbnb: A case of home rental. Annals of Tourism Research, 75, 279-287.

Ert, E., Fleischer, A., \& Magen, N. (2016). Trust and reputation in the sharing economy: The role of personal photos in Airbnb. Tourism Management, 55, 62-73.

Eugenio-Martin, J. L., Cazorla-Artiles, J. M., \& González-Martel, C. (2019). On the determinants of Airbnb location and its spatial 
distribution. Tourism 1354816618825415.

Fang, B., Ye, Q., \& Law, R. (2016). Effect of sharing economy on tourism industry employment. Annals of Tourism Research, 57(3), 264-267.

Fereday, J., \& Muir-Cochrane, E. (2006). Demonstrating rigor using thematic analysis: A hybrid approach of inductive and deductive coding and theme development. International journal of qualitative methods, 5(1), 80-92.

Guo, Y., Barnes, S. J., \& Jia, Q. (2017). Mining meaning from online ratings and reviews: Tourist satisfaction analysis using latent dirichlet allocation. Tourism Management, 59, 467-483.

Gurran, N., \& Phibbs, P. (2017). When tourists move in: how should urban planners respond to Airbnb?.Journal of the American planning association, 83(1), 80-92.

Gursoy, D., Cai, R., \& Anaya, G. J. (2017). Developing a typology of disruptive customer behaviors: Influence of customer misbehavior on service experience of by-standing customers. International Journal of Contemporary Hospitality Management, 29(9), 2341-2360

Guttentag, D. (2015). Airbnb: disruptive innovation and the rise of an informal tourism accommodation sector. Current issues in Tourism, 18(12), 1192-1217.

Guttentag, D. A., \& Smith, S. L. (2017). Assessing Airbnb as a disruptive innovation relative to hotels: Substitution and comparative performance expectations. International Journal of Hospitality Management, 64, 1-10.

Guttentag, D., Smith, S., Potwarka, L., \& Havitz, M. (2018). Why tourists choose Airbnb: A motivation-based segmentation study. Journal of Travel Research, 57(3), 342-359.

Hamari, J., Sjöklint, M., \& Ukkonen, A. (2016). The sharing economy: Why people participate in collaborative consumption. Journal of the association for information science and technology, 67(9), 2047-2059.

Heo, Y. (2016). Sharing economy and prospects in tourism research. Annals of Tourism Research, 58, 166-170.

Hu, Y. H., Chen, Y. L., \& Chou, H. L. (2017). Opinion mining from online hotel reviews-A text summarization approach. Information Processing \& Management, 53(2), 436-449.

Hussain, S., Ahmed, W., Jafar, R. M. S., Rabnawaz, A., \& Jianzhou, Y. (2017). eWOM source credibility, perceived risk and food product customer's information adoption. Computers in Human Behavior, 66, 96-102.

Ju, Y., Back, K. J., Choi, Y., \& Lee, J. S. (2019). Exploring Airbnb service quality attributes and their asymmetric effects on customer satisfaction. International Journal of Hospitality Management, 77, 342-352.

Kastenholz, E., Carneiro, M. J., Marques, C. P., \& Loureiro, S. M. C. (2018). The dimensions of rural tourism experience: impacts on arousal, memory, and satisfaction. Journal of Travel \& Tourism Marketing, 35(2), 189-201.

Khoo-Lattimore, C., \& Ekiz, E. H. (2014). Power in praise: Exploring online compliments on luxury hotels in Malaysia. Tourism and Hospitality Research, 14(3), 152-159.

Kim, J. H., Ritchie, J. R., \& Tung, V. W. S. (2010). The effect of memorable experience on behavioral intentions in tourism: A structural equation modeling approach. Tourism Analysis, 15(6), 637648.

Kim, W. G., Lim, H., \& Brymer, R. A. (2015). The effectiveness of managing social media on hotel performance. International Journal of Hospitality Management, 44, 165-171.

Kozak, M., \& Rimmington, M. (2000). Tourist satisfaction with Mallorca, Spain, as an off-season holiday destination. Journal of travel research, 38(3), 260-269.

Kozinets, R. V. (2002). The field behind the screen: Using netnography for marketing research in online communities. Journal of marketing research, 39(1), 61-72.

Kozinets, R. V. (2007). Netnography 2.0. In R. W. Belk (Ed.), Handbook of qualitative research methods in marketing(pp. 129-42). Cheltenham, UK: Edward Elgar Publishing.

Ladhari, R., \& Michaud, M. (2015). eWOM effects on hotel booking intentions, attitudes, trust, and website perceptions. International Journal of Hospitality Management, 46, 36-45.

Lalicic, L., \& Weismayer, C. (2017). The role of authenticity in Airbnb experiences. In Information 
and Communication Technologies in Tourism 2017 (pp. 781-794). Springer, Cham.

Leong, L. Y., Hew, T. S., Ooi, K. B., \& Lin, B. (2019). Do electronic Word of-mouth and elaboration likelihood model influence hotel booking?. Journal of Computer Information Systems, 59(2), 146-160.

Liang, L. J., Choi, H. C., \& Joppe, M. (2018). Exploring the relationship between satisfaction, trust and switching intention, repurchase intention in the context of Airbnb. International Journal of Hospitality Management, 69, 41-48.

Lin, P. M., Fan, D. X., Zhang, H. Q., \& Lau, C. (2019). Spend less and experience more: Understanding tourists' social contact in the Airbnb context. International Journal of Hospitality Management, 83, 65-73.

Liu, J. N., \& Zhang, E. Y. (2014). An investigation of factors affecting customer selection of online hotel booking channels. International Journal of Hospitality Management, 39, 71-83.

Liu, S. Q., \& Mattila, A. S. (2017). Airbnb: Online targeted advertising, sense of power, and consumer decisions. International Journal of Hospitality Management, 60, 33-41.

Liu, Y., Teichert, T., Rossi, M., Li, H., \& Hu, F. (2017). Big data for big insights: Investigating language-specific drivers of hotel satisfaction with 412,784 user-generated reviews. Tourism Management, 59, 554-563.

Lo, A. S., \& Yao, S. S. (2019). What makes hotel online reviews credible? An investigation of the roles of reviewer expertise, review rating consistency and review valence. International Journal of Contemporary Hospitality Management, 31(1), 41-60.

Lune, H., \& Berg, B. L. (2016). Qualitative research methods for the social sciences. Pearson Higher Ed.

Luo, Y., \& Tang, R. L. (2019). Understanding hidden dimensions in textual reviews on Airbnb: An application of modified latent aspect rating analysis (LARA). International Journal of Hospitality Management, 80, 144-154.

Lutz, C., \& Newlands, G. (2018). Consumer segmentation within the sharing economy: The case of Airbnb. Journal of Business Research, 88, 187-196.
Lyu, J., Li, M., \& Law, R. (2019). Experiencing P2P accommodations: Anecdotes from Chinese customers. International Journal of Hospitality Management, 77, 323-332.

Martin, C. J. (2016). The sharing economy: A pathway to sustainability or a nightmarish form of neoliberal capitalism?. Ecological economics, 121, 149-159.

Masiero, L., Yang, Y., \& Qiu, R. T. (2019). Understanding hotel location preference of customers: Comparing random utility and random regret decision rules. Tourism Management, 73, 83-93.

Min, H., Lim, Y., \& Magnini, V. P. (2015). Factors affecting customer satisfaction in responses to negative online hotel reviews: The impact of empathy, paraphrasing, and speed. Cornell Hospitality Quarterly, 56(2), 223-231.

Mody, M., Hanks, L., \& Dogru, T. (2019). Parallel pathways to brand loyalty: Mapping the consequences of authentic consumption experiences for hotels and Airbnb. Tourism Management, 74, 65-80.

Moon, H., Wei, W., \& Miao, L. (2019). Complaints and resolutions in a peer-to-peer business model. International Journal of Hospitality Management, 81, 239-248.

Neal, J. D., \& Gursoy, D. (2008). A multifaceted analysis of tourism satisfaction. Journal of Travel Research, 47(1), 53-62.

Nvivo 12, (2019). 10 Nisan 2019 tarihinde https://www.qsrinternational.com/nvivo/nvivoproducts adresinden alınmıştır.

Oskam, J., \& Boswijk, A. (2016). Airbnb: the future of networked hospitality businesses. Journal of Tourism Futures, 2(1), 22-42.

Park, S., Yang, Y., \& Wang, M. (2019). Travel distance and hotel service satisfaction: An inverted U-shaped relationship. International journal of hospitality management, 76, 261-270.

Paulauskaite, D., Powell, R., Coca-Stefaniak, J. A., \& Morrison, A. M. (2017). Living like a local: Authentic tourism experiences and the sharing economy. International Journal of Tourism Research, 19(6), 619-628.

Phillips, P., Zigan, K., Silva, M. M. S., \& Schegg, R. (2015). The interactive effects of online reviews on the determinants of Swiss hotel performance: A 
neural network analysis. Tourism Management, 50, 130-141.

Priporas, C. V., Stylos, N., Vedanthachari, L. N., \& Santiwatana, P. (2017). Service quality, satisfaction, and customer loyalty in Airbnb accommodation in Thailand. International Journal of Tourism Research, 19(6), 693-704.

Radojevic, T., Stanisic, N., \& Stanic, N. (2015). Ensuring positive feedback: Factors that influence customer satisfaction in the contemporary hospitality industry. Tourism Management, 51, 1321.

Ren, L., Zhang, H. Q., \& Ye, B. H. (2015). Understanding customer satisfaction with budget hotels through online comments: Evidence from Home Inns in China. Journal of Quality Assurance in Hospitality \& Tourism, 16(1), 45-62.

Rice, J., \& Khanin, D. (2019). Why Do They Keep Coming Back? The Effect of Push Motives vs. Pull Motives, and Attribute Satisfaction on Repeat Visitation of Tourist Destinations. Journal of Quality Assurance in Hospitality \& Tourism, 1-25.

Sangpikul, A. (2018). The effects of travel experience dimensions on tourist satisfaction and destination loyalty: the case of an island destination. International Journal of Culture, Tourism and Hospitality Research, 12(1), 106-123.

Schor, J. (2016). Debating the sharing economy. Journal of Self-Governance and Management Economics, 4(3), 7-22.

Schuckert, M., Liang, S., Law, R., \& Sun, W. (2019). How do domestic and international highend hotel brands receive and manage customer feedback?. International Journal of Hospitality Management, 77, 528-537.

So, K. K. F., Oh, H., \& Min, S. (2018). Motivations and constraints of Airbnb consumers: Findings from a mixed-methods approach. Tourism Management, 67, 224-236.

Sotiriadou, P., Brouwers, J., \& Le, T. A. (2014). Choosing a qualitative data analysis tool: A comparison of NVivo and Leximancer. Annals of Leisure Research, 17(2), 218-234.

Sukhu, A., Choi, H., Bujisic, M., \& Bilgihan, A. (2019). Satisfaction and positive emotions: A comparison of the influence of hotel guests' beliefs and attitudes on their satisfaction and emotions. International Journal of Hospitality Management, 77, 51-63.
Tussyadiah, I. P. (2015). An exploratory study on drivers and deterrents of collaborative consumption in travel. Içinde Information and communication technologies in tourism 2015(pp. 817-830). Springer, Cham.

Tussyadiah, I. P. (2016). Factors of satisfaction and intention to use peer-to-peer accommodation. International Journal of Hospitality Management, 55, 70-80.

Varma, A., Jukic, N., Pestek, A., Shultz, C. J., \& Nestorov, S. (2016). Airbnb: Exciting innovation or passing fad?.Tourism Management Perspectives, 20, 228-237.

Walls, A., Okumus, F., Wang, Y., \& Kwun, D. J. W. (2011). Understanding the consumer experience: An exploratory study of luxury hotels. Journal of Hospitality Marketing \& Management, 20(2), 166-197.

Wang, C. R., \& Jeong, M. (2018). What makes you choose Airbnb again? An examination of users' perceptions toward the website and their stay. International Journal of Hospitality Management, 74, 162-170.

Xiang, Z., Schwartz, Z., Gerdes Jr, J. H., \& Uysal, M. (2015). What can big data and text analytics tell us about hotel guest experience and satisfaction?. International Journal of Hospitality Management, 44, 120-130.

Xu, F., La, L., Zhen, F., Lobsang, T., \& Huang, C. (2019). A data-driven approach to guest experiences and satisfaction in sharing. Journal of Travel \& Tourism Marketing, 36(4), 484-496.

$\mathrm{Xu}, \mathrm{X}$., \& Li, Y. (2016). The antecedents of customer satisfaction and dissatisfaction toward various types of hotels: A text mining approach. International journal of hospitality management, 55, 57-69.

Yang, Y., Mao, Z., \& Tang, J. (2018). Understanding guest satisfaction with urban hotel location. Journal of Travel Research, 57(2), 243259.

Ye, Q., Law, R., Gu, B., \& Chen, W. (2011). The influence of user-generated content on traveler behavior: An empirical investigation on the effects of e-word-of-mouth to hotel online bookings. Computers in Human behavior, 27(2), 634-639.

Ye, Q., Li, H., Wang, Z., \& Law, R. (2014). The influence of hotel price on perceived service 
quality and value in e-tourism: An empirical investigation based on online traveler reviews. Journal of Hospitality \& Tourism Research, 38(1), 23-39.

Yen, C. L. A., \& Tang, C. H. H. (2015b). Hotel attribute performance, eWOM motivations, and media choice. International Journal of Hospitality Management, 46, 79-88.

Yen, C. L. A., \& Tang, C. H. H. (2019a). The effects of hotel attribute performance on electronic word-of-mouth (eWOM) behaviors. International Journal of Hospitality Management, 76, 9-18.

Zekan, B., Önder, I., \& Gunter, U. (2019). Benchmarking of Airbnb listings: How competitive is the sharing economy sector of European cities?. Tourism Economics, 1-18

Zervas, G., Proserpio, D., \& Byers, J. W. (2017). The rise of the sharing economy: Estimating the impact of Airbnb on the hotel industry. Journal of Marketing Research, 54(5), 687-705.

Zhang, J. (2019). What's yours is mine: exploring customer voice on Airbnb using text-mining approaches. Journal of Consumer Marketing.

Zhao, Y., Xu, X., \& Wang, M. (2019). Predicting overall customer satisfaction: big data evidence from hotel online textual reviews. International Journal of Hospitality Management, 76, 111-121. 